\title{
The vaccination lie and why you should get a booster shot nevertheless.
}

\author{
Dr. Carolina Diamandis ${ }^{1}$, Joachim Schmidt ${ }^{1}$, Jonathan Feldman ${ }^{1}$, and David Seideman ${ }^{1}$
}

${ }^{1}$ Affiliation not available

November 23, 2021

\begin{abstract}
Vaccinated people think they are completely immune to Covid-19 and cannot infect others. This is a false assumption. In November 2020, Europe was on the brink of a triage situation. Now it's November again, a year later, and the situation has worsened despite vaccination campaigns. What went wrong?
\end{abstract}

\section{Hosted file}

Vaccination lie.pdf available at https://authorea.com/users/410930/articles/546590-thevaccination-lie-and-why-you-should-get-a-booster-shot-nevertheless 